\title{
Adjunct Support for High School ESL Learners in Mainstream English Classes: Ensuring Success
}

\section{Hetty Roessingh}

The demographic profile of Alberta is changing rapidly. As the new millennium approaches, new patterns of immigration to Canada, and hence Alberta, are emerging and are forcing educators to rethink the goals of ESL instruction. The current wave of immigrants has expectations for academic success. Educational attention must be focused on programmatic responses that will ensure that ESL learners develop the level of English language proficiency necessary for academic success in high school and postsecondary study. Adjunct ESL instruction that complements the demands of high school English literature courses can result in the development of English language proficiency, and in turn academic success for ESL learners.

\section{Introduction}

Over the past decade, the demographics of our immigrant population have changed noticeably. Immigration statistics from various sources (Employment and Immigration Canada, 1985; Alberta Advanced Education and Career Development, 1995; Citizenship and Immigration Canada, 1997) reflect three significant trends that have a direct impact on ESL programming at the high school level. First, there has been a shift from refugee class to independent class immigrants (including business class immigrants). In 1985, the federal government initiated a plan to recruit and select business immigrants in recognition of their significant economic benefit to Canada through increased capital formation and job creation (Employment and Immigration Canada, 1985). Independent class immigrants are assessed for immigration according to a point system that takes into account factors such as education and knowledge of English.

Second, although there is still diversity among the new immigrants of the 1990s, Hong Kong now far outstrips any other country as a source of origin for new Canadians, and Cantonese is the most common first language spoken among these new arrivals. Between 1984 (Employment and Immigration Canada, 1985) and 1994 (Citizenship and Immigration Canada, 1997) immigration from Hong Kong increased from $15 \%$ to $34 \%$ of the total number of immigrants from the top 10 source countries. In actual numbers, this is an increase from 7,696 to 44,174 immigrants from Hong Kong in that decade, 
approximately a sixfold increase. In 1994, Alberta received 4,005 of these immigrants (Alberta Advanced Education and Career Development, 1995), with Hong Kong in the number one position of source countries of immigration.

Third, there has been a steady increase in the numbers of immigrants to Canada over that decade. In the mid-1980s, Canada's immigration target was approximately 110,000 (Employment and Immigration, 1985). By the mid 1990s, the immigration target was set at approximately 225,000 (Citizenship and Immigration Canada, 1997). Most of these new Canadians do not speak English. School jurisdictions in large urban centers such as Calgary (Dawson, 1998; Dempster \& Alberts, 1998), Toronto (McInnes, 1993) and Vancouver (Rinehart, 1996) estimate that ESL students form $20 \%$ to over $50 \%$ of the general student population in the K-12 system. ESL is fast becoming the mainstream in the major urban centers of Canada.

In implementing a learner-centered focus to ESL program design, it becomes clear that the time has arrived to revisit the goals of ESL instruction as well as to develop new working relationships with our colleagues in administration, guidance, and mainstream English instruction. The learning profile of a significant number of our current ESL high school students that emerges from the demographic data reflects high academic abilities and the desire to pursue academic studies at the university level. Meeting university entrance requirements, particularly the English literature course requirements, is a major challenge for ESL students. They must do so when they are still linguistically disadvantaged in mainstream class settings.

This article is intended for ESL teachers, school administrators, guidance counselors, and mainstream English teachers at the high school level. It begins by providing the background information that establishes the rationale for the shift in program design. It proposes a framework for developing the academic proficiency of ESL learners. It gives details about how an adjunct block of time can be used to complement mainstream English literature instruction in an urban, academically oriented high school. It provides a summary of some of the quantitative outcomes of the adjunct/English course. The article concludes by arguing for adjunct ESL support comprising integrated language-learner strategies-concept teaching that will foster a balance in the equation of mainstream content linked to ESL programming. A sample template for a three-year high school diploma that qualifies for university entrance is included in Appendix A.

\section{Background}

Tracking studies of high school ESL student achievement carried out over the past 10 years (Watt \& Roessingh, 1994, 1999) indicate that successful graduation from high school remains an elusive goal for most ESL students. Watt and Roessingh recorded a $74 \%$ dropout rate among high school ESL 
learners tracked over a 10-year period. ESL students proceed at great risk of academic failure and dropout after they exit from ESL programs, and struggle in mainstream course settings. Other studies of ESL dropout rates in Alberta (Alberta Education, 1992) and British Columbia (Eddy, 1999) mirror these findings. These dropout figures represent an enormous loss of human capital in Canada's future as many of these students are among the strongest academic learners in the school. Significant numbers of these ESL learners excel in the mathematics and sciences (Marshall, 1999).

Canada's economy is increasingly driven by electronic technology or communications in the new age of information (Francis, 1998). Our new immigrants can, wish to, and expect to contribute to the new economy of the 21st century. They can do so only if they can develop the academic English language proficiency required for success (Watt, Roessingh, \& Bosetti, 1996a). Attention must therefore be focused on programmatic responses that will develop the level of English language proficiency necessary for academic success for our new incoming ESL students of the 1990s.

A promising response for stemming the dropout rate for these students would be to extend ESL support to include an adjunct component for the most linguistically demanding courses in the mainstream: the English literature courses. Although adjunct courses are not a new idea, past initiatives of this kind have tended to focus on university and college-level students (Harding, 1981; Snow \& Brinton, 1988; Gee, 1990). Little in the research literature offers specificity to classroom practitioners at the high school level on the implementation of this adjunct approach to ESL learners' needs. At the level of strategy-interventions and lesson-planning (Kidd \& Marquardson, 1997; Oxford, 1990; Chamot \& O'Malley, 1987) advice is to be found in the literature, but these issues are more at the microlevel.

In general, these interventions assume that the students' language learning needs will emerge from the content requirement of mainstream courses such as English. "Content should be the primary focus of instruction and academic language skills can be developed as the need for them emerges from the content" (Chamot \& O'Malley, 1994, p. 26). Kidd and Marquardson (1997) build on Chamot and O'Malley's CALLA approach with an application for lesson planning, called Foresee, and it "like CALLA is a contentdriven approach" (p. 2).

I take the position that we need to be clear that the ESL teachers are the educators with the expertise to be proactive in responding to ESL learners' needs. ESL students' language learning needs for success in high school English are predictable, and it is these needs that should drive ESL instruction, not the content. The content is seen as a vehicle for the development of English language proficiency, and it-along with how it is sequenced-can be negotiated at least to some extent with the English literature teacher. What is more, the learning needs go beyond both the development of English 
language proficiency and learning strategies and include the acquisition of foundational concepts and background knowledge that are contextualized by way of the particular culture in which we live and the literary traditions reflected in the English curriculum. Successful engagement with the English literature curriculum, therefore, assumes three things: English language proficiency, learning strategies, and concept understandings and background knowledge embedded in cultural information. These become the focus of the planned adjunct curriculum.

\section{A Model for the Development of Academic Proficiency}

The above discussion suggests a tripartite model of programming for the development of academic proficiency comprising English language proficiency, learning strategies, and the acquisition of underlying concepts and background knowledge relevant to the English literature curriculum. Figure 1 illustrates this three-dimensional framework (Roessingh, 1995). Each component is discussed briefly below.

\section{English Language Proficiency Among ESL Learners}

Much has been written over the past 15 years about the development of English language proficiency among ESL learners. Perhaps the key realization over these years has been that conversational fluency is not sufficient for

\begin{tabular}{|c|c|c|}
\hline & \multicolumn{2}{|c|}{$\begin{array}{l}\text { Language Proficiency } \\
\text { - Viewing } \\
\text { - Listening } \\
\text { - Speaking } \\
\text { - participates in class discussions } \\
\text { - Reading } \\
\text { - Writing } \\
\text { - writes essays }\end{array}$} \\
\hline $\begin{array}{l}\text { Learning Strategies } \\
\text { - Cognitive strategies } \\
\text { - selective underlining or } \\
\text { highlighting, and annotating of text } \\
\text { for future review } \\
\text { - using a bilingual dictionary } \\
\text { - using context to guess at meaning } \\
\text { - Metacognitive strategies } \\
\text { - regulates, manages. monitors own } \\
\text { learning } \\
\text { - Socioaffective strategies } \\
\text { - cooperative learning/group work }\end{array}$ & 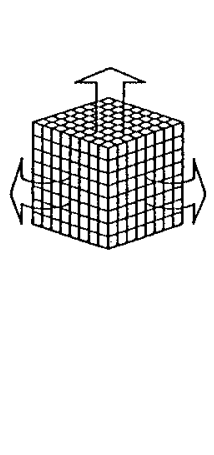 & $\begin{array}{l}\text { Concepts } \\
\text { - A belief in destiny and fate shapes the } \\
\text { individual's or culture's world view } \\
\text { - Inook and the Sun } \\
\text { - Romeo and Juliet } \\
\text { - Rituals are a reflection of a culture's } \\
\text { basic belief system } \\
\text { - Inook and the Sun } \\
\text { - The essential human condition } \\
\text { transcends language, time, culture } \\
\text { - A great love story is durable, } \\
\text { universally accessible and appreciated } \\
\text { - Romeo and Juliet }\end{array}$ \\
\hline
\end{tabular}


success in an academic environment. Language and cognition are inextricably linked. Cummins' $(1982,1994)$ conceptual framework for the development of basic interpersonal communication skills (BICS) and cognitive academic language proficiency (CALP) is widely accepted not only among ESL educators, but increasingly among mainstream teachers as ESL students move into and become the mainstream. The framework is useful in helping school administrators and guidance counselors understand the process of secondlanguage acquisition (Figure 2).

The framework is organized along two continua: from cognitively undemanding to cognitively demanding activities ( $x$ axis) and from context embedded to context reduced situations ( $y$ axis). The resulting four quadrants form the framework for designing and sequencing learning tasks and for identifying the extent to which ESL students are able to cope successfully with the cognitive and linguistic demands made on them by the social and educational environment in which they are obliged to function. Quadrants 1 and 2 are typically in the realm of BICS: the language developed is not cognitively challenging, and the context for language development is highly embedded in the students' knowledge of the world of the here-and-now (quadrant 1). If the context is not in the here-and-now, it is within the lived experiences of the students and thus easily accessible as a springboard for language development (quadrant 2). ESL learners are generally able to become proficient with basic interpersonal communication skills within approximately two years of arrival (Cummins, 1994).

Quadrant 3 is a transition phase where students may successfully be integrated into mainstream mathematics and science courses (Roessingh, 1996). Hands-on lab work and visual representations make the content accessible to ESL learners, and high-school-aged students are often able to transfer what they already know about the content into English. Thus these settings

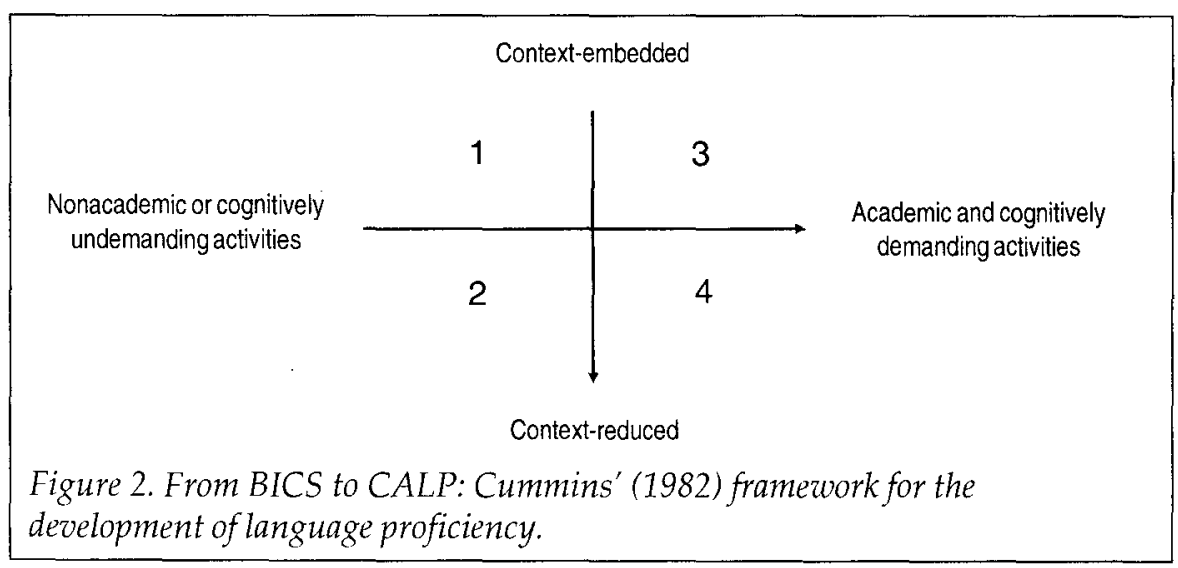


serve as places where students may use the content as a vehicle for ESL development.

Quadrant 4 is the phase of greatest challenge, for the content is accessible only through language itself. The content is often remote, abstract, and laden with cultural references and the language of imagery, symbolism, and metaphor. It may take from five to seven years (or longer) for ESL learners to reach this level of language proficiency (Collier, 1987, 1989).

Figure 3 compares the language proficiencies pertinent to academic success that ESL learners can be expected to have on entry into quadrant 4 with those of their native English-speaking peers (in the academic high school stream).

ESL learners quickly become aware of the enormous linguistic demand of the academic mainstream: "When I was in ESL, I thought I was quite good in English, but getting into a real classroom and it turned out it wasn't so. That's like starting over again" (Watt, Roessingh, \& Bosetti, 1996b, p. 211).

This student's comment is telling: it suggests that ESL support needs to be extended beyond the point where in the past ESL educators would have recommended exit from the ESL program. In fact, the ESL students' language learning needs do not come to an end, but shift and change as the demands of integration into the mainstream shift and change.

\section{Learning Strategies}

Students who are linguistically disadvantaged can partly override the effects of this challenge by deploying strategies that are directly taught to them (Kern, 1989). A number of strategies have been identified that appear to be especially useful (Davis \& Bistodeau, 1993). Oxford and Crookall (1989) provide a good overview of the research on language learning strategies. Chamot and O'Malley (1987) propose three broad categories of learning

$\begin{array}{ll}\text { ESL Learners } & \text { Native English-Speaking Learners } \\ 5,000-7,000 \text {-word vocabulary* } & 40,000 \text {-word vocabulary** } \\ \begin{array}{l}\text { Reading speed: approx. } 100 \text { wpm (narrative } \\ \text { materials) }\end{array} & \text { Approx. } 300 \text { wpm } \\ \text { Reading grade equivalent: } 6 \text { or } 7 & \text { Reading at grade level (10) or higher } \\ \text { Difficulty with writing in expository mode } & \text { Writing skills assumed } \\ \text { Familiar with standard English only } & \text { Familiar with a variety of dialects (e.g., Ebonics, } \\ & \text { the language of children) } \\ \text { Lacking experience with puns, double meanings, } & \text { Enjoy humor based on language } \\ \text { idioms } & \\ \text { *Grabe (1987). } & \\ \text { **Miller \& Gildea (1991). } & \\ \text { Figure 3. Proficiencies pertinent to academic success. }\end{array}$


strategies: cognitive, metacognitive, and socioaffective. The adjunct ESL block of time can exploit mainstream content to focus on developing online reading strategies such as contextual guessing to make sense of new vocabulary, making predictions and conclusions, inferring, and monitoring for comprehension.

\section{Foundational Understanding of Concepts and Background Knowledge}

Foundational understanding of concepts and knowledge about how the world works are embedded in the values, traditions, rituals, and belief systems that children acquire by living in a particular cultural milieu. These understandings and knowledge may be thought of as cultural capital. Study of literature reflects these understandings. ESL learners exhibit large gaps in cultural information and background knowledge assumed for placement in an academic English literature course. Examples might include understanding the way of life and cultural traditions of the Canadian Inuit people (e.g., "Inook and the Sun," a modern drama selection), and the language of metaphor that is so prevalent in the writing of Shakespeare (a requirement in many English literature courses at the high school level).

Language skills, learning strategies, and concepts are not learned in a vacuum. They may be contextualized by way of the content provided by an academic English literature course, for example. This linkage is the crucial connection in making adjunct ESL programming and mainstream English literature instruction successful.

\section{An Adjunct Block}

An adjunct block may be described as an ESL course that is linked to a content area course (e.g., English literature). ESL students are enrolled in both courses concurrently and, at least in this case, receive credit for each. The adjunct block in this program was scheduled for equal time to the literature course ( 125 hours). The courses share the same content base and complement each other in terms of mutually coordinated assignments (Snow \& Brinton, 1988). A key feature of this design is the coordination and collaborative planning on the part of the ESL instructor and the content area instructor (Canada College, 1991). The content area course is taught by a teacher with expertise in that area, whereas the ESL adjunct is taught by an ESL instructor.

Ideally, the English literature class is sheltered. That is to say, it includes only ESL learners, at least for the introductory level (grade 10) course. A number of benefits accrue for the ESL learners by sheltering the grade 10 English literature course: 
- genre may be studied in greater depth, less breadth (e.g., fewer short stories, but with greater understanding through detailed study);

- students' ability to use their first language to acquire their second language may be respected, promoted, and enhanced through structuring certain assignments (e.g., translate a short story from L1 into English);

- the mainstream teacher becomes more sensitive to the particular demands of the literature curriculum that are challenging for ESL learners and begins to make adjustments at whatever level possible;

- the mainstream teacher joins with his or her ESL teacher colleagues to advocate on behalf on ESL learners who need various types of ongoing supports in the mainstream setting.

\section{Implementing an Adjunct Block}

What follows is a discussion of the practical considerations for implementing an adjunct ESL block linked to an academic English literature course (English 10 ) in a small, urban, academically oriented high school of 600 students. The ESL students have mostly come from the Pacific Rim (Hong Kong, Taiwan, Korea). The learning profile of these students was diverse, but generally the students arrived at age 16 and were reading at approximately 4.5 grade equivalent (GE) on their arrival. They were placed in grade 10, and they were "in a hurry." Like many other ESL learners, they needed to see direct relevance between their ESL time and their mainstream educational goals (Kanno \& Applebaum, 1995). After one year in an advanced ESL class and integration into physical education, sciences, and mathematics (where a lower linguistic threshold is sufficient for academic success), a group of 23 students was placed in a grade 10 sheltered English literature class with an adjunct block for support. They are now in their second year in Canada and reading at approximately a 6-7 GE.

ESL learners in this school must write the same end-of-semester examination as all other students registered for the grade 10 English course. Moreover, ESL students must write the same grade 12 provincial English examination as all other students province-wide who have registered for grade 12 English. ESL students are not given extra time to write this examan issue for advocacy action, because other "coded" students (e.g., learningdisabled students, deaf and hard of hearing students) are given double the time allocation in recognition of the deficit in language processing time these students live with in completing their academic work.

An adjunct block of time to complement an English literature course was used to give direct instruction in the components of academic proficiency discussed above, namely, language proficiency, learning strategies, and foundational concepts or background knowledge. The adjunct block pro- 
vided two critical elements to contribute to ESL students' success: additional time and collaborative planning between teachers.

\section{Time}

The theme of needing time is expressed by students in the following ways (Watt et al., 1996b):

I always thought I could know more English, but I can't you know. It's good in ESL. They teach you slowly and over and over. For me, for English, I would like to stay one more year. They push me so muchtoo fast-I can't handle it. I don't know why they push the students so hard. (p. 211)

The teacher explains in a class and you have to catch on quickly which is hard for a slow memory. And then you have to write down whatever he says. (p. 212)

Students themselves recognize the need for many exposures and opportunities to recycle and practice new vocabulary and concepts that are already familiar to their native English-speaking classmates. ESL students need extra time to process and develop language, to do homework, to write formal exams, to write and rewrite papers, and to manage and pace their work to complete a novel study. In time, the gap between the ESL students' achievement level and the achievement level of their native English-speaking classmates may diminish as a consequence of natural maturational processes, together with the benefits of instructed ESL support. However, as Collier (1989) notes, ESL learners will always be chasing a moving target, and it will take many years for ESL learners to compete on an equal footing with their academic peers.

\section{Collaborative Planning}

Collaborative planning among ESL and English mainstream teachers ensures a tight fit between the demands of the literature class and the support given in the adjunct block. Several issues are sure to arise as a result of attempting to take into consideration the students' ESL learning needs (in the adjunct block) and the pressure they are under to compete with native English-speaking counterparts for final course marks in the English literature course. Collaborative planning needs to include the selection and sequencing of the content for the English literature course within the constraints of the curriculum requirements, assignments and how they will be marked and weighted, and special considerations for writing examinations.

English teachers typically have some discretion and flexibility in choosing the content and deciding how it is sequenced and organized to meet the course requirements. In this case, five units of study (genre-driven) were required. Collaborative planning and negotiating between the ESL teacher 
and the English teacher led to the following sequence: modern drama, short stories, a novel study, a selection from Shakespeare, and poetry. Another approach might have been to organize the content thematically, integrating the genres for study into units such as "The Human Spirit" or "No Other Love." The content was chosen in part with the ESL learners' interests, background knowledge, possibilities for linkages to other curriculum areas (e.g., social studies), and level of English language proficiency in mind; and in part by the constraints of the learning resources available in the school and the comfort level of the English teacher to take on an innovative approach of sheltered English linked to the adjunct block. It was agreed that depth of content coverage was more important than breadth; hence less content was chosen to address the curriculum requirements than would normally be the case with native English-speaking students. Had the English class not been sheltered, the English teacher would have had to deal with this consideration for ESL learners in an integrated setting.

The adjunct block and English course teachers generally kept assignments separate for purposes of determining marks, but often structured assignments collaboratively and designed them to complement one another's courses. Often assignments were handed back and forth between the teachers before being returned to the students in order to monitor student progress and to get a sense of expectations for achievement in each setting. Good communication between the two teachers as well as with the students (and their parents) was important in helping students understand their report card and final marks, particularly in the English course where they had difficulty accepting marks in the $60-70 \%$ range. A downside of offering a sheltered English course, then, is that ESL students lack firsthand exposure and understanding of what it is to compete for marks in an integrated setting. Although ESL students have tended to be the top students in mathematics and sciences where the linguistic threshold for academic success is much lower and they have received good marks for their work in an ESL setting, the demands of an English literature course are not well understood by them. They will learn soon enough.

ESL students must write the same final English exam as all other students registered in the course at the school. However, in keeping with regulations for other learners with exceptional needs (learning-disabled and deaf and hard of hearing students) attending this school, the ESL students were allowed up to double the time scheduled to write the English 10 exam. Also, they wrote the exam in a separate classroom rather than in the large gym. Again, this is a point for discussion not only with the English teacher, but with the English department as a whole. Not all English teachers (or for that matter ESL instructors) would agree that ESL learners should be granted these special privileges. 
To summarize, time and collaborative planning are the keys to the success of the ESL learners as they move into the most linguistically demanding courses in their high school program. ESL learners will be disadvantaged from a variety of perspectives in mainstream English settings, mainly due to their lower level of English language proficiency and their different cultural background knowledge. The goal, therefore, is to plan for the continued development of English language proficiency while making the regular or mainstream class setting accessible to ESL learners.

\section{Some Quantitative Results}

All 23 ESL students in the adjunct class passed both the final examination and the English 10 course. This contrasts with earlier findings that ESL students are at heightened academic risk and failure at this point in the educational trajectory, apparently due to premature integration in mainstream classrooms (Watt \& Roessingh, 1999).

The success or failure of the 23 ESL students was assessed by comparing pre- and post-reading scores using the Gates MacGinitie (MacGinitie \& MacGinitie, 1992) tests. Students whose initial reading comprehension score was below a 7 GE were unsuccessful at achieving marks in English 10 exceeding $65 \%$ (the level recommended for placement in grade 11 academic English). These students will be asked to take an additional English course (a nonacademic grade 11 course) to develop their English language proficiency before attempting English 20 (academic-level grade 11 English). Students whose reading comprehension was at least $7 \mathrm{GE}$ and who had a final reading comprehension score of at least $8 \mathrm{GE}$ were successful in achieving the scores required for placement in grade 11 academic English.

Gains were reflected in both vocabulary and reading comprehension scores for all students. However, gains in reading comprehension were greater than gains in vocabulary. It may be that ESL students reach a stage where they can apply reading strategies such as contextual guessing to make meaning at the discourse level, and once they have reached this threshold, gains in reading comprehension scores seem to accelerate quickly. Decontextualized vocabulary items are clearly a challenge for ESL learners, and their scores on this subtest of the Gates MacGinitie lag behind the scores on the reading comprehension subtest by approximately 2 GE. They remain enormously disadvantaged in terms of the breadth and depth of the vocabulary generally assumed necessary for academic success in high school for native English-speaking students. In addition, reading speed remained slow (approximately 150 words per minute) for the ESL learners, given reading materials at their pre- and post-reading GE scores.

These findings suggest a minimum linguistic threshold of $7 \mathrm{GE}$ for placement in a grade 10 academic English course (assuming the students read at grade level in L1). Students appear to be able to mediate this three-year gap 
in the development of their English language proficiency with instructional support and time. At this level of English language proficiency, students appear competent to use the content of English 10 to advance their reading skills rapidly enough to succeed with grade 11 materials within just 20 weeks (i.e., one semester).

Further tracking of those ESL students who immediately registered for grade 11 academic English (integrated setting) reflects further success. In fact, their English marks have often increased as the students unleash the abstract thoughts and images they can communicate by acquiring the level of English language proficiency required to do so.

\section{Conclusion}

The demographics of our ESL population have changed. The new ESL learner is more academically oriented than in the past. ESL students will probably not be able to compete on an equal footing with their native English-speaking counterparts any time during their high school years due to the length of time it is known to take for CALP-like proficiency to develop. It takes many years for ESL learners to develop the level of English language proficiency that will allow them to learn academic content area materialsand specifically English literature-independently (Collier, 1987, 1989; Collier \& Thomas, 1989). The key to their ultimate success, therefore, is the development of English language proficiency using content area materials wisely and appropriately as a vehicle to advance this language development. We need to seek a new balance in the language through content equation. Failure to do so often results in overstuffed but undernourished students: students who have neither a good grasp of the content, nor the English language required to access it. Low plateau, early fossilization, failure, and dropout are real hazards of language-through-content approaches that overemphasize content learning at the expense of a language learning focus (Roessingh, 1996).

To remain learner-centered means that the language learning needs of the student must drive our instructional planning, rather than a textbook- or content-driven curriculum. Team teaching between teachers with ESL and English literature expertise can address this issue. Our focus needs to be on student success in developing the English language proficiency, concepts, and learning strategies our students need to become independent and lifelong learners. As ESL educators we must take the lead in establishing new working partnerships with our mainstream colleagues. Together we can be stronger in advocating on behalf of ESL learners to introduce initiatives that will level the playing field and allow these students to demonstrate more fully their real achievement.

Canada's demographic landscape will certainly continue to change as global forces together with Canada's domestic immigration policy fluctuate 
(Robillard, 1999; Dawson, 1998). Canada will be rejuvenated and recreated continually, as this is the ethos of the Canadian identity. As caring and professionally committed educators we must be prepared to identify and respond in a proactive manner to the changing learning needs of the young men and women who seek to make their future in Canada and become the new generation of Canadian citizens of the 21st century.

\section{Acknowledgments}

I am grateful for strong support of the ESL program by the administrative team, especially Diane Field, principal; the guidance team, especially Chuck Eastly; and the English Department, especially Ben Bombier who took on the challenge of teaching the sheltered English 10 course. Sincere thanks are extended to my colleague Dora Foscolos for helpful comments about the article in its earlier stages and to three anonymous reviewers for their thoughtful input for revisions to the manuscript. Finally, a special thanks goes to Patrick Mathews, editor, TESL Canada Journal for his patience, support, and direction in bringing the manuscript to publication.

\section{The Author}

Hetty Roessingh is a full-time high school ESL teacher with the Calgary Board of Education. Her interests include action research, tracking studies, and curriculum design and development. The most recent challenge has been to respond to the learning needs of the new wave of immigrants to Alberta from the Pacific Rim. Hetty is also a sessional instructor on ESL teaching methods and research in the Faculty of Education, University of Calgary.

\section{References}

Alberta Advanced Education and Career Development. (1995). Immigration to Alberta 1993-1994. Derived from IMM10001993 and 1994 Preliminary Statistics. Ottawa, ON: Citizenship and Immigration Canada.

Alberta Education. (1992). Achieving the vision report. Edmonton, AB: Alberta Education.

Canada College. (1991). English institute content-based program manual. Redwood City, CA: Canada College. (ERIC Document Reproduction Service No. ED 333 924)

Chamot, A., \& O'Malley, M. (1987). The cognitive academic language learning approach: A bridge to the mainstream. TESOL Quarterly, 21, 227-247.

Chamot, A., \& O'Malley, (1994). The CALLA handbook: Implementing the cognitive academic language learning approach. Don Mills, ON: Addison-Wesley.

Citizenship and Immigration Canada. (1997). Staying the course: 1997 annual immigration plan. Ottawa, ON: Author.

Collier, V. (1987). Age and rate of acquisition of second languages for academic purposes. TESOL Quarterly, 21, 617-641.

Collier, V. (1989). How long? a synthesis of research on academic achievement in a second language. TESOL Quarterly, 23, 509-531.

Collier, V., \& Thomas, W. (1989): How quickly can immigrants become proficient in school English? Journal of Educational Issues of Minority Students, 5, 26-38.

Cummins, J. (1982). Tests, achievement, and bilingual students. Focus No. 9, Feb. 1982. Wheaton, MD: National Clearinghouse for Bilingual Education.

Cummins, J. (1994). The acquisition of English as a second language. In K.SpangenbergUrbschat \& R. Pritchard (Eds.), Kids come in all languages (pp. 36-62). Newark, DE: International Reading Association.

Davis, J., \& Bistodeau, L. (1993). How do L1 and L2 reading differ? Evidence from think aloud protocols. Modern Language Journal, 77, 459-472. 
Dawson, C. (1998, November 14). ESL student numbers strain public board. Calgary Herald, B9.

Dempster, L., \& Alberts, S. (1998, February 18). Calgary a leader in ethnic minorities. Calgary Herald, A1-2.

Eddy, C. (1999, May). The forces who shape us. Paper presented to the TESL '99 Conference, Meeting the Millennium, Banff.

Employment and Immigration Canada. (1985). Annual report to parliament on future immigration levels. Ottawa, ON: Author.

Francis, D. (1998, October 31). Our high-tech brain cramp. Financial Post, D3.

Gee, Y. (1990). An ESL adjunct class for Asian American studies. (ERIC Document Reproduction Service No. ED 352812 )

Harding, I. (1981). Adjunct courses: Integrating study skills into content courses. (ERIC Document Reproduction Service No. ED 208 339)

Kanno, Y., \& Applebaum, S. (1995). ESL students speak up: Their stories of how we are doing. TESL Canada Journal, 12(2), 32-49.

Kern, R. (1989). Second language reading strategy instruction: Its effects on comprehension and word inference ability. Modern Language Journal, 73, 135-149

Kidd, R., \& Marquardson, B. (1997). The Foresee approach to integrated ESL instruction. TESL Canada Journal, 15(1) 1-21.

MacGinite, W., \& MacGinitie, R. (1992). Gates-MacGinitie reading tests, second edition, levels E and F. Scarborough, ON: Nelson.

Marshall, A. (1999 March 15). Immigrants score better in high school. Calgary Herald, A-1,2.

McInnes, C. (1993, May 3). First you have to learn English. Globe and Mail, A1.

Oxford, R. (1990). Language learning strategies: What every teacher should know. New York: Newbury House.

Oxford, R., \& Crookall, D. (1989). Research on language learning strategies: Methods, findings, and instructional issues. Modern Language Journal, 73, 404-419.

Snow, M., \& Brinton, D. (1988). Content-based language instruction: Investigating the effectiveness of the adjunct model. TESOL Quarterly, 22, 553-574.

Rinehart, D. (1996, November 21). The ESL quandary. Vancouver Sun, Saturday Review, D4-5.

Robillard, L. (1999, February). Building on a strong foundation for the 21st century at Citizenship and Immigration Canada. Liberal Times, 5-8.

Roessingh, H. (1995). Teaching to diversity: Meaningful inclusion of ESL students in high school mainstream settings. Exceptionality Education, 5(1), 65-83.

Roessingh, H. (1996). ESL students and the inclusive high school science class: An investigation into the effects of curriculum restructuring. Unpublished doctoral dissertation, University of Calgary.

Watt, D., \& Roessingh, H. (1994). ESL dropout: The myth of educational equity. Alberta Journal of Educational Research, 40, 283-296.

Watt, D., \& Roessingh, H. (1999). A ten year tracking study of ESL students. Unpublished manuscript, Faculty of Education, University of Calgary.

Watt, D., Roessingh, H., \& Bosetti, L. (1996a). Educational experiences of ESL students: Unravelling the role of English language proficiency. In K. McLeod (Ed.), Multicultural education, The state of the art national study, Report No. 4 (pp 126-133). Winnipeg, MB: Canadian Association of Second Language Teachers.

Watt, D., Roessingh, H., \& Bosetti, L. (1996b). Success and failure: Stories of ESL students' educational and cultural adjustment to high school. Urban Education, 31, 199-221. 


\section{Appendix A \\ A Sample Template for a Three-Year High School Program Based on a Semester System}

\begin{tabular}{|c|c|c|}
\hline Grade 10 & Grade 11 & Grade 12 \\
\hline \multicolumn{3}{|l|}{ Semester 1} \\
\hline ESL & English 10: sheltered & English 20 or English 30 \\
\hline ESL & ESL Adjunct & ESL tutorial \\
\hline PE 10 & Social Studies 23 & Math 30 \\
\hline Math 10 & Physics, Math or Chemistry 20 & Physics 30 or Chemistry 30 or Biology 20 \\
\hline \multicolumn{3}{|l|}{ Semester 2} \\
\hline ESL & English 20 or 23 & English 30 \\
\hline Science 10 & $\mathrm{ES} L$ tutorial & ESL tutorial \\
\hline Social Studies 13 & Social Studies 33 & Chemistry 30 or Physics 30 \\
\hline CALM/CTS $^{*}$ & Physics, Math or Chemistry 30 & Math 31 or Biology 30 \\
\hline Summer school & Summer school & Summer school \\
\hline $\begin{array}{l}\text { Math } 20 \text { or Physics } 20 \\
\text { or Chemistry } 20\end{array}$ & $\begin{array}{l}\text { Math } 20 \text { or Physics } 20 \\
\text { or Chemistry } 20\end{array}$ & Biology $30 ?$ \\
\hline
\end{tabular}

${ }^{*}$ Career and Technology Studies: note that students must present 10 credits (the equivalent of two full courses) in $\mathrm{CTS}$ for graduation requirements. Many students can do this by presenting Chinese credits earned at Saturday school. Some students decide to focus on university faculty entrance requirements and forfeit a high school diploma. No faculty requires CTS credits.

Note. Alberta Learning, the Ministry for education in Alberta, allocates only 15 credits (the equivalent of 3 full courses of 125 instructional hours each) for ESL programming at the high school level. Other credits, such as Reading 10 or Communications $21 \mathrm{~A} / \mathrm{B}$ may be assigned to students' instructional programs. ESL students, however, often spend hundreds of hours in ESL class settings for no credit. ESL students capture the full funding for credit equivalent units (CEUs) whether or not their ESL time is assigned credit. Supplementary funding for ESL as well as the three-year cap is in flux in Alberta at the present time.

For more information on credit equivalents and course requirements for graduation, consult the Alberta Learning websites: www.alis.gov.ab.ca or http://ednet.edc.gov.ab.ca 